\title{
Field Emission Properties of Carbon Nanotubes with Boron Doping and $\mathrm{H}_{2} \mathrm{O}$ Adsorption
}

\author{
Yijun Wang, ${ }^{1}$ Liuding Wang, ${ }^{2}$ and Cheng Yan ${ }^{3}$ \\ ${ }^{1}$ School of Physics and Electronic Engineering, Xianyang Normal University, Xianyang 712000, China \\ ${ }^{2}$ School of Science, Northwestern Polytechnical University, Xi'an 710129, China \\ ${ }^{3}$ Science and Technology on Low-Light-Level Night Vision Laboratory, Xian 710065, China \\ Correspondence should be addressed to Yijun Wang; 806605363@qq.com
}

Received 22 August 2013; Accepted 18 November 2013

Academic Editor: Ashkan Vaziri

Copyright (C) 2013 Yijun Wang et al. This is an open access article distributed under the Creative Commons Attribution License, which permits unrestricted use, distribution, and reproduction in any medium, provided the original work is properly cited.

\begin{abstract}
Gas adsorption and atom doping usually present when preparing carbon nanotubes (CNTs) and can affect the field emission properties of carbon nanotubes. $\mathrm{H}_{2} \mathrm{O}$ molecule and boron atom are the most important adsorbates, respectively. Using ab-initio calculations, we have investigated the electron field emission performance of $\mathrm{CNTs}$ simultaneously adsorbed with one $\mathrm{H}_{2} \mathrm{O}$ molecule and doped with one boron atom $\left(\mathrm{BCNT}+\mathrm{H}_{2} \mathrm{O}\right)$ in this paper. The results indicate that the electrons localize at the top of $\mathrm{BCNT}+\mathrm{H}_{2} \mathrm{O}$ and the electronic density of states (DOS) around the Fermi level is enhanced obviously. It is expected that $\mathrm{BCNT}+\mathrm{H}_{2} \mathrm{O}$ will be more propitious to the field emission of electrons based on the calculations of DOS, HOMO/LUMO, and Mulliken charge population.
\end{abstract}

\section{Introduction}

Carbon nanotubes (CNTs) have attracted much attention due to their high aspect ratio and remarkable mechanical, electronic, and chemical properties [1-3]. The quasi-one-dimensional structures and unique electric properties make CNTs have a lot of potential applications in different fields [4-6]. Especially, because of the excellent field emission properties, CNTs have been promising candidates for flat-panel displays $[7,8]$. Up to now, many experimental [9] and theoretical [1012] studies have shown that the gas adsorption is of great advantage to the electron emission of the CNTs. For example, Kim et al. calculated the DOS and field emission properties of closed CNTs under electric field [13], Maiti et al. explained the reason why $\mathrm{H}_{2} \mathrm{O}$ adsorption on the top of CNTs can improve the electron emission properties [14], and Zhang et al. pointed out that CNTs doped with boron and nitrogen are easy to emit electrons [15].

Naturally, some kinds of gas can markedly change the energy band structure of carbon nanotubes, whereas the work of simultaneous doping and adsorption is rarely reported until now. Therefore, it is very important to study the emission properties of CNTs doped with other atoms and adsorbed with gases under electric field. In this paper we adopted the density functional theory (DFT) to investigate the performances of $\mathrm{BCNT}+\mathrm{H}_{2} \mathrm{O}$.

\section{Models and Calculation Methods}

A single-walled armchair $(5,5)$ CNT with a cap (Figure 1) is adopted. The cap is a hemisphere ( 30 carbon atoms) of $\mathrm{C}_{60}$ at one end of the CNT and the dangling bonds at the other end are saturated by hydrogen atoms. The position of boron dope is selected at the top layer of the $\mathrm{CNT}$ and the distance of $\mathrm{H}_{2} \mathrm{O}$ adsorption from the top pentagon is about $0.3 \mathrm{~nm}$. Therefore the whole system contains 93 atoms.

All the calculations were carried out by using first-principle DFT provided by $\mathrm{DMOL}^{3}$ code [16]. The geometrical optimization was based on the local density approximation (LDA) during self-consistent field iteration with the PerdewWang parameterization of the local exchange correlation energy. The generalized gradient approximation (GGA) was adopted to calculate the total energy and various electronic properties with the Perdew-Wang-91 (PW91) function [17]. The all-electron Kohn-Sham wave functions were expanded 


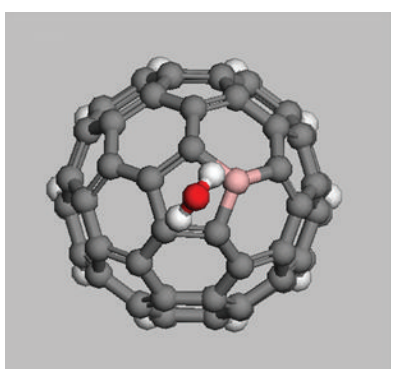

(a)

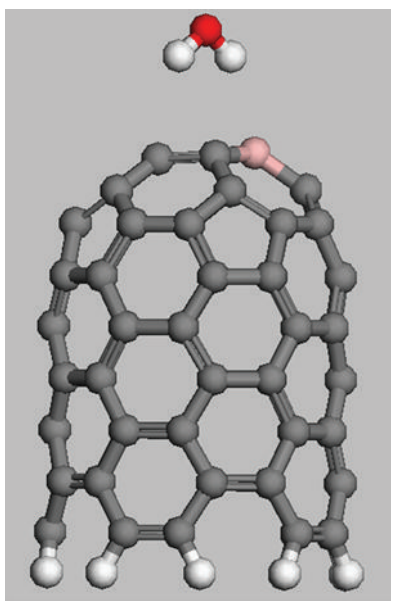

(c)

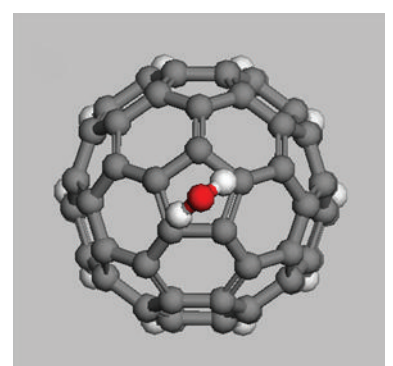

(b)

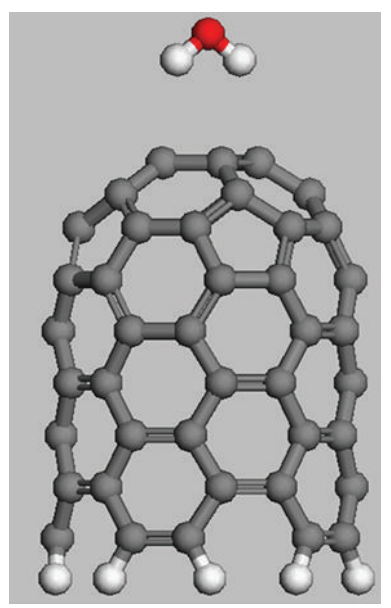

(d)
FIgURE 1: The structures of $\mathrm{BCNT}+\mathrm{H}_{2} \mathrm{O}$ and $\mathrm{CNT}+\mathrm{H}_{2} \mathrm{O}$. (a) and (b) are the top views; (c) and (d) are the side views of $\mathrm{BCNT}+\mathrm{H}_{2} \mathrm{O}$ and $\mathrm{CNT}+\mathrm{H}_{2} \mathrm{O}$, respectively.

in the local atomic orbital basis set with orbital cutoff of $4.5 \AA$. Self-consistent field procedure was done with a convergence criterion of $10^{-5}$ a.u. on the energy and electron density.

\section{Results and Discussion}

In order to study the electronic field emission properties of $\mathrm{BCNT}+\mathrm{H}_{2} \mathrm{O}$, a uniform external electric field with the direction from the top to the end of the CNT is applied, whose intensities are $E=0$ and $E=10 \mathrm{eV} / \mathrm{nm}$, respectively. In real field emission conditions, a short tip of the structures is considered. The electric field gradient along CNTs axis is ignored and the whole structure is supposed to be in a uniform external electric field [17].

The adsorption distance and adsorption energy are shown in Table 1 . The adsorption energy $\left(W_{\text {ad }}\right)$ under the different electric field is defined in (1) and (2), respectively. Consider the following:

$$
\begin{aligned}
& W_{\mathrm{ad}(E=0)} \\
& =W_{\mathrm{CNTs}(E=0)}+W_{\mathrm{H}_{2} \mathrm{O}(E=0)}-W_{\mathrm{CNT}+\mathrm{H}_{2} \mathrm{O}(E=0)}, \\
& W_{\mathrm{ad}(E=10 \mathrm{eV} / \mathrm{nm})} \\
& =W_{\mathrm{CNTs}(E=10 \mathrm{eV} / \mathrm{nm})} \\
& \quad+W_{\mathrm{H}_{2} \mathrm{O}(E=0)}-W_{\mathrm{CNT}+\mathrm{H}_{2} \mathrm{O}(E=10 \mathrm{eV} / \mathrm{nm})},
\end{aligned}
$$

TABLE 1: The adsorption distance (nm) and adsorption energy $(\mathrm{eV})$ of $\mathrm{CNT}+\mathrm{H}_{2} \mathrm{O}$ and $\mathrm{BCNT}+\mathrm{H}_{2} \mathrm{O}$ systems with and without electric field $(\mathrm{eV} / \mathrm{nm})$.

\begin{tabular}{lcccc}
\hline \multirow{2}{*}{ Systems } & \multicolumn{2}{c}{$E=0 \mathrm{eV} / \mathrm{nm}$} & \multicolumn{2}{c}{$E=10 \mathrm{eV} / \mathrm{nm}$} \\
& Distance/nm & Energy/eV & Distance & Energy \\
\hline $\mathrm{CNT}+\mathrm{H}_{2} \mathrm{O}$ & 0.307 & 0.03 & 0.300 & 0.91 \\
$\mathrm{BCNT}+\mathrm{H}_{2} \mathrm{O}$ & 0.315 & 0.09 & 0.310 & 1.34 \\
\hline
\end{tabular}

Table 2: Pseudogap (eV) and DOS (electron/eV) at $E_{f}$ under different electric field $(\mathrm{eV} / \mathrm{nm})$.

\begin{tabular}{lcccc}
\hline \multirow{2}{*}{ Systems } & \multicolumn{2}{c}{$E=0 \mathrm{eV} / \mathrm{nm}$} & \multicolumn{2}{c}{$E=10 \mathrm{eV} / \mathrm{nm}$} \\
& DOS at $E_{f}$ & Pseudogap & DOS at $E_{f}$ & Pseudogap \\
\hline $\mathrm{CNT}+\mathrm{H}_{2} \mathrm{O}$ & 3.14 & 3.34 & 10.56 & 2.12 \\
$\mathrm{BCNT}+\mathrm{H}_{2} \mathrm{O}$ & 10.61 & 2.10 & 18.56 & 1.61 \\
\hline
\end{tabular}

where the $W_{\mathrm{CNTs}(E=0)}, W_{\mathrm{H}_{2} \mathrm{O}(E=0)}$, and $W_{\mathrm{CNT}+\mathrm{H}_{2} \mathrm{O}(E=0)}$ are the total energy of the pure CNT, the adsorbate $\left(a \mathrm{H}_{2} \mathrm{O}\right.$ molecule), and the adsorbed CNT system, respectively, under the strength of electric field of $0 \mathrm{eV} / \mathrm{nm}$, and where $W_{\mathrm{CNTs}(E=10 \mathrm{eV} / \mathrm{nm})}$ and $W_{\mathrm{CNT}+\mathrm{H}_{2} \mathrm{O}(E=10 \mathrm{eV} / \mathrm{nm})}$ have the same meaning under the strength of electric field of $10 \mathrm{eV} / \mathrm{nm}$.

From Table 1, we can see that the adsorption distance is about $0.3 \mathrm{~nm}$ and the adsorption energy is very small for $\mathrm{BCNT}+\mathrm{H}_{2} \mathrm{O}$ and $\mathrm{CNT}+\mathrm{H}_{2} \mathrm{O}$ systems in the absence of electric field. When the electric field increases to $10 \mathrm{eV} / \mathrm{nm}$, their adsorption energy is remarkably enhanced, while their adsorption distance decreases slightly. Moreover, Table 1 shows that the adsorption energy of $\mathrm{BCNT}+\mathrm{H}_{2} \mathrm{O}$ is much higher than that of $\mathrm{CNT}+\mathrm{H}_{2} \mathrm{O}$ under the same strength of electric field, which indicates that the structure of $\mathrm{BCNT}+\mathrm{H}_{2} \mathrm{O}$ is more stable [18] than that in a electron transmitter.

Figure 2 presents the DOS of the two systems under the different electric fields and the local density of states (LDOS) of the boron atom and the nearest three carbon atoms on the top of $\mathrm{BCNT}+\mathrm{H}_{2} \mathrm{O}$ under $E=10 \mathrm{eV} / \mathrm{nm}$. Obviously, the DOS plots of the two systems shift towards the low energy direction and their corresponding peak positions of antibond states are more close to $E_{f}$ when the electric fields increase from 0 to $10 \mathrm{eV} / \mathrm{nm}$. This indicates that the probability of electron occurrence at antibond states increase, which is well consistent with Kim's conclusion [13].

To determine the pseudogap, an advanced peak separation technique [19] is adopted. Furthermore, the DOS at $E_{f}$ is also calculated, as listed in Table 2. When the electric fields increase from 0 to $10 \mathrm{eV} / \mathrm{nm}$, the DOS of the two systems at $E_{f}$ enhances by a big margin. Especially the DOS of BCNT $+\mathrm{H}_{2} \mathrm{O}$ is about $179 \%$ that of $\mathrm{CNT}+\mathrm{H}_{2} \mathrm{O}$ at $E=10 \mathrm{eV} / \mathrm{nm}$. The reasons can be found from Figure 2(e) that the peak position of LDOS for $\mathrm{BCNT}+\mathrm{H}_{2} \mathrm{O}$ tip is very close to Fermi level, which leads to the enhancement of DOS at $E_{f}$. Moreover, we can infer that the external electric field significantly weakens the covalent bond and enhances 


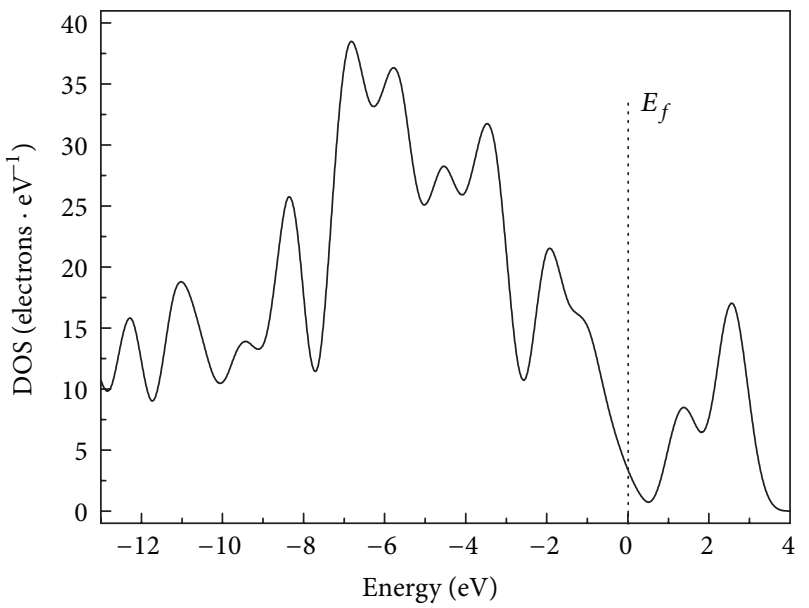

(a)

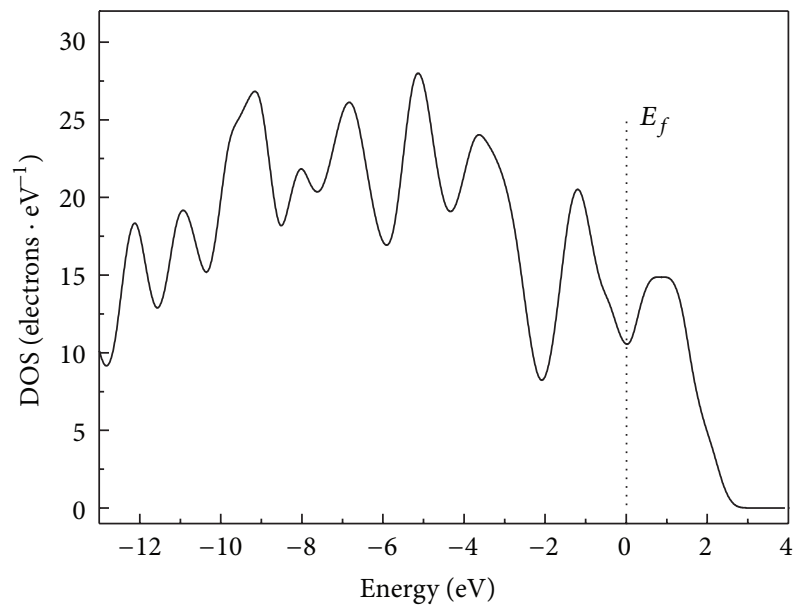

(c)

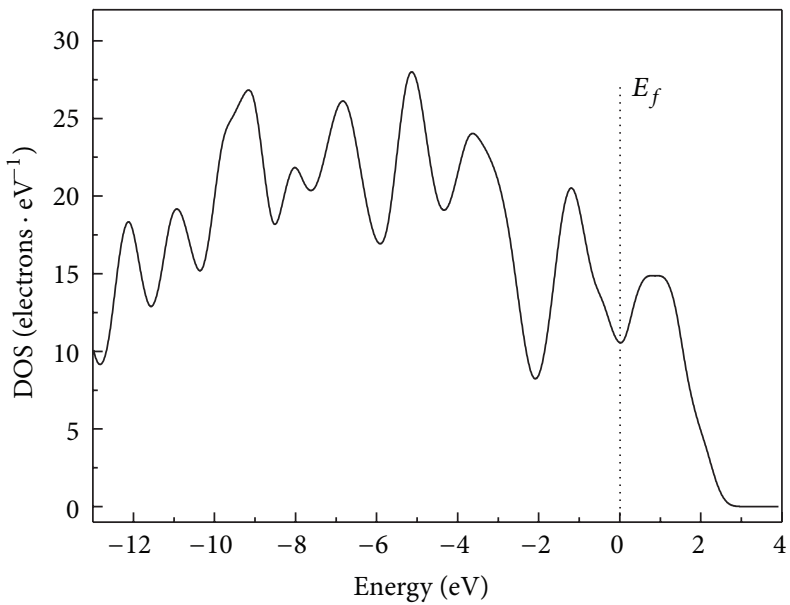

(b)

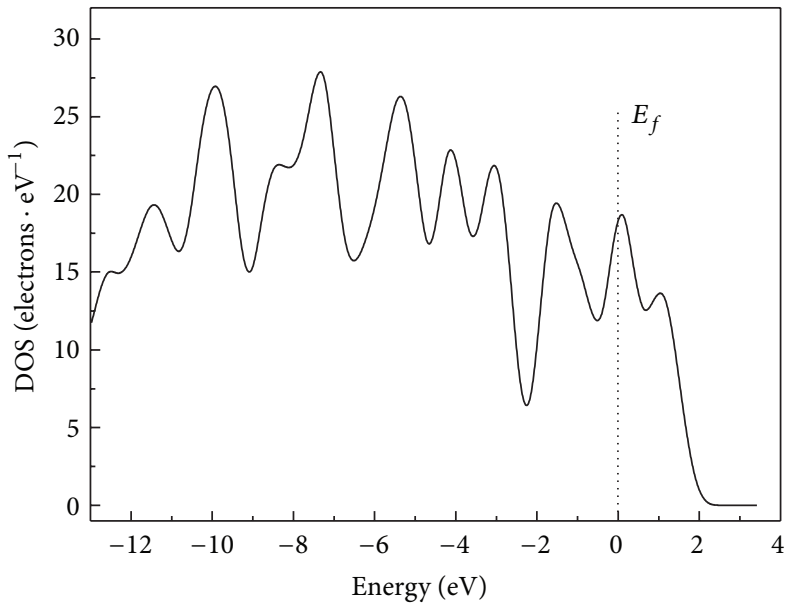

(d)

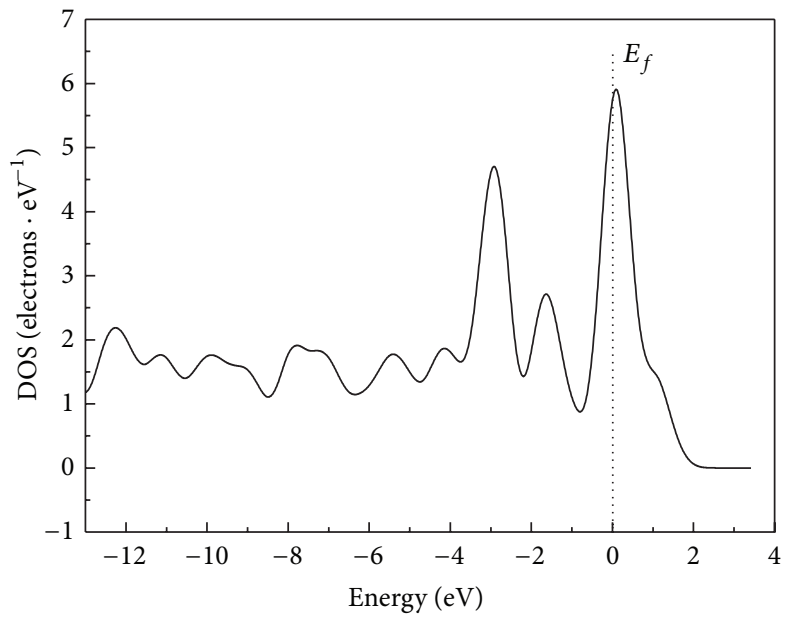

(e)

FIGURE 2: DOS plots of $\mathrm{CNT}+\mathrm{H}_{2} \mathrm{O}$ and $\mathrm{BCNT}+\mathrm{H}_{2} \mathrm{O}$ under the different electric field. (a) and (c) are DOS of $\mathrm{CNT}+\mathrm{H}_{2} \mathrm{O}$ and $\mathrm{BCNT}+\mathrm{H}_{2} \mathrm{O}$ without electric field, (b) and (d) are DOS of $\mathrm{CNT}+\mathrm{H}_{2} \mathrm{O}$ and $\mathrm{BCNT}+\mathrm{H}_{2} \mathrm{O}$ under $E=10 \mathrm{eV} / \mathrm{nm}$, and (e) is LDOS of a boron and 3 carbon atoms of $\mathrm{BCNT}+\mathrm{H}_{2} \mathrm{O}$ under $E=10 \mathrm{eV} / \mathrm{nm}$, respectively. 


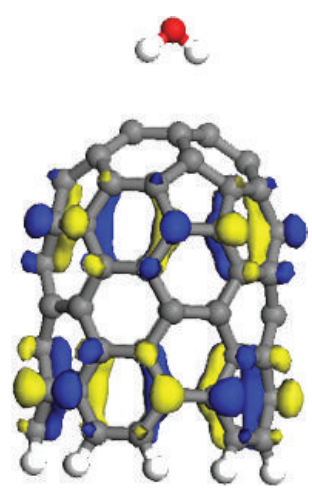

(a)

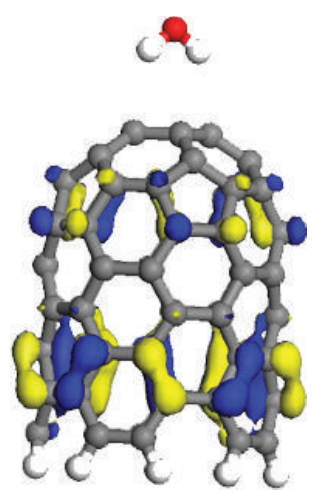

(e)

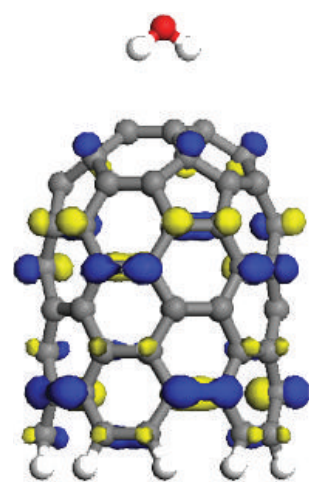

(b)

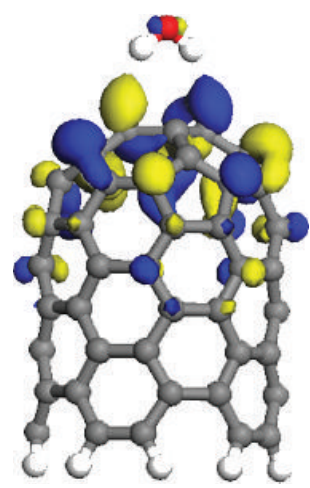

(f)

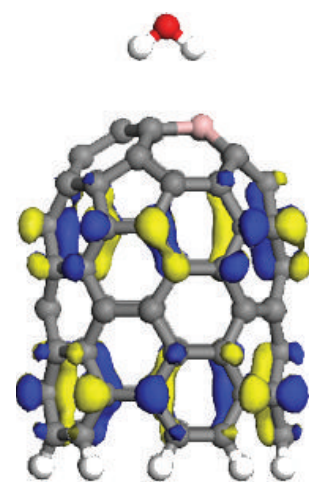

(c)

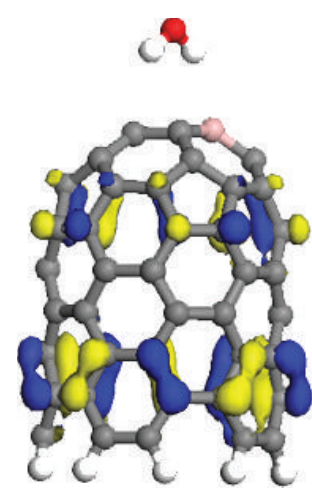

(g)

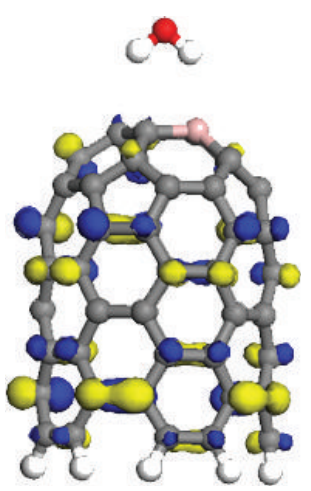

(d)

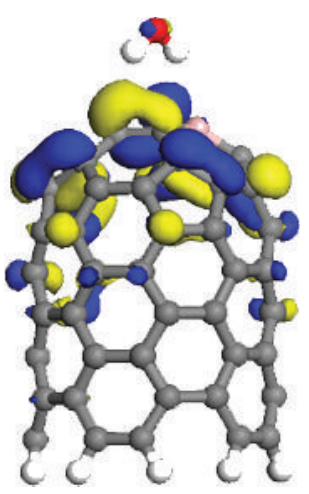

(h)

FIGURE 3: Side views of the charge density under different electric field: (a), (b) and (c), (d) refer to $\mathrm{HOMO} / \mathrm{LUMO}$ of $\mathrm{CNT}+\mathrm{H}_{2} \mathrm{O}$ and $\mathrm{BCNT}+\mathrm{H}_{2} \mathrm{O}$ without electric field, respectively. (e), (f) and (g), (h) refer to HOMO/LUMO of $\mathrm{CNT}+\mathrm{H}_{2} \mathrm{O}$ and $\mathrm{BCNT}+\mathrm{H}_{2} \mathrm{O}$ under $E=$ $10 \mathrm{eV} / \mathrm{nm}$, respectively.

the metallic bond from the pseudogap of $\mathrm{BCNT}+\mathrm{H}_{2} \mathrm{O}$ compared with $\mathrm{CNT}+\mathrm{H}_{2} \mathrm{O}$. Therefore, the calculated results and theoretical analysis above mentioned indicate consistently that the electron transmission in $\mathrm{BCNT}+\mathrm{H}_{2} \mathrm{O}$ is much easier and the corresponding field emission properties can be effectively improved compared with $\mathrm{CNT}+\mathrm{H}_{2} \mathrm{O}$.

To further investigate the field emission property of $\mathrm{BCNT}+\mathrm{H}_{2} \mathrm{O}$, we have performed the electronic orbital analysis. As shown in Figure 3, the HOMOs of $\mathrm{CNT}+\mathrm{H}_{2} \mathrm{O}$ and $\mathrm{BCNT}+\mathrm{H}_{2} \mathrm{O}$ are all localized at their body and the distribution is very similar no matter whether the electric field is applied or not. However, the LUMO of later is mainly localized at the tip of CNTs at $E=10 \mathrm{eV} / \mathrm{nm}$.

This means that there are more electrons congregating on the top region of $\mathrm{BCNT}+\mathrm{H}_{2} \mathrm{O}$. Once the stronger electric field is applied these electrons immediately emit to the surrounding space. It can be seen that the conclusions of orbital analysis are well consistent with that of the discussion above.

When a boron atom substitutes a carbon atom in the top layer, the charges distribution and the electronic structures change accordingly. Figure 4 exhibits the results of Mulliken population analysis for the $\mathrm{CNT}+\mathrm{H}_{2} \mathrm{O}$ and $\mathrm{BCNT}+\mathrm{H}_{2} \mathrm{O}$ in the presence of $E=10 \mathrm{eV} / \mathrm{nm}$. We can see that the boron atom carries a little negative charge and each of the nearest three carbon atoms carries much more negative charges than other atoms located in the first and second layer [20]. The analysis results show that the boron doping can cause more electrons aggregation at the top. Essentially, the electron congregation becomes more obvious with the increase of applied electric field and extra electrons on the tip of system will congregate in the conduction band. Consequently the Fermi level shifts toward the vacuum level. This will lower the potential barrier of $\mathrm{BCNT}+\mathrm{H}_{2} \mathrm{O}$ tip and make the field emission more easily. All of these discussions indicate that $\mathrm{BCNT}+\mathrm{H}_{2} \mathrm{O}$ can enhance the electron field emission.

\section{Conclusions}

In summary, we investigate the electronic structure and physical mechanism of the fieldemission of the capped SWNT which are simultaneously adsorbed with one $\mathrm{H}_{2} \mathrm{O}$ molecule and doped by a boron atom in the top layer. The calculations and analysis confirm that $\mathrm{BCNT}+\mathrm{H}_{2} \mathrm{O}$ has a higher DOS at $E_{f}$ than $\mathrm{CNT}+\mathrm{H}_{2} \mathrm{O}$. Although the $\mathrm{HOMO}$ of $\mathrm{BCNT}+\mathrm{H}_{2} \mathrm{O}$ changes hardly with and without the applied electric field, the LUMO is highly localized at the top. Furthermore, the Mulliken population analysis shows that a lot of electrons congregate at the cap of $\mathrm{BCNT}+\mathrm{H}_{2} \mathrm{O}$. Naturally, present results of the LDOS, the pseudogap, the HOMO/LUMO, and Mulliken population analysis congruously indicate that 


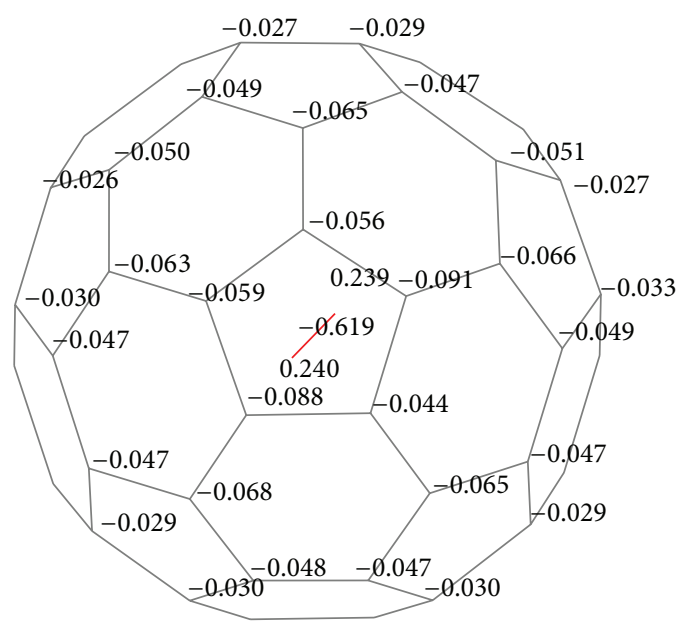

(a)

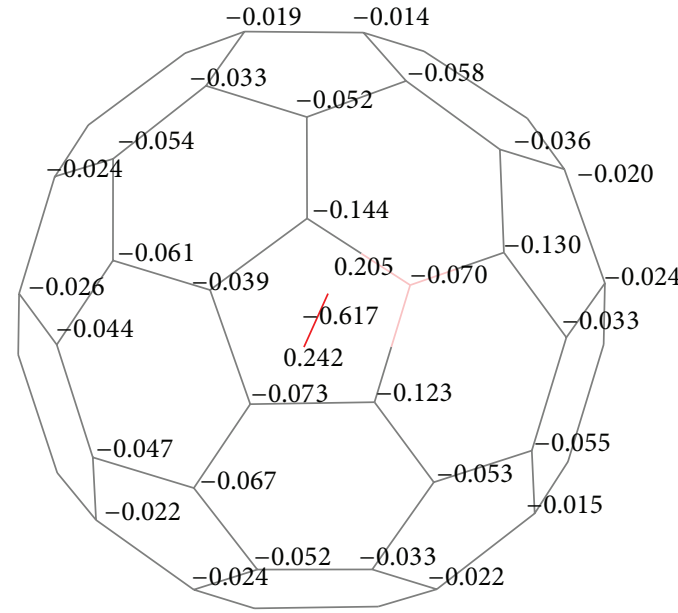

(b)

FIGURE 4: Mulliken population analysis of $\mathrm{CNT}+\mathrm{H}_{2} \mathrm{O}$ (a) and $\mathrm{BCNT}+\mathrm{H}_{2} \mathrm{O}$ (b) under $E=10 \mathrm{eV} / \mathrm{nm}$.

$\mathrm{BCNT}+\mathrm{H}_{2} \mathrm{O}$ can effectively improve the fieldemission properties of carbon nanotubes compared with $\mathrm{CNT}+\mathrm{H}_{2} \mathrm{O}$.

\section{Conflict of Interests}

The authors, hereby, declare that they do not have any conflict of interests.

\section{Acknowledgments}

This work was financially supported by the National Natural Science Foundation of China (11075135, 61307002), the Natural Science Foundation of Shaanxi Province (no. 2012JM1009), the Scientific Research Program of Shaanxi Provincial Education Department (no. 12JK0984), the Scientific Research Program (nos. 12XSYK014, 12XSYK017), and the Teaching Reform Research Program of Xianyang Normal University (no. 201200127), China.

\section{References}

[1] S. Iijima, "Helical microtubules of graphitic carbon," Nature, vol. 354, no. 6348, pp. 56-58, 1991.

[2] C. Hierold, O. Brand, G. K. Fedder, J. G. Korvink, and O. Tabata, Carbon Nanotube Devices: Properties, Modeling, Integration and Applications, vol. 8 of Advanced Micro \& Nanosystems, Wiley$\mathrm{VCH}, 2008$

[3] A. V. Eletskii, "Carbon nanotube-based electron field emitters," Physics-Uspekhi, vol. 53, no. 9, pp. 863-892, 2010.

[4] J. Ali, A. Kumar, S. Husain, M. Kumari, H. Harsh, and M. Husain, "Characterization and field emission studies of uniformly distributed multi-walled carbon nanotubes (MWCNTS) film grown by low-pressure chemical vapour deposition (LPCVD)," Current Nanoscience, vol. 7, no. 3, pp. 333-336, 2011.

[5] S. M. Lupekhin and A. A. Ibragimov, "Field emission of electrons from a single carbon fiber with a nanostructured emitting surface," Technical Physics, vol. 57, no. 1, pp. 119-123, 2012.

[6] E. F. Zharikova, L. I. Ochertyanova, I. V. Vasylenko et al., "Multi-walled carbon nanotubes with the pyridine-containing fragment and copper(II) ions," Russian Chemical Bulletin, vol. 61, no. 7, pp. 1430-1436, 2012.

[7] V. Guglielmotti, E. Tamburri, S. Orlanducci et al., "Macroscopic self-standing SWCNT fibres as efficient electron emitters with very high emission current for robust cold cathodes," Carbon, vol. 52, no. 2, pp. 356-362, 2013.

[8] N. Perea-López, B. Rebollo-Plata, J. A. Briones-León et al., "Millimeter-long carbon nanotubes: outstanding electron-emitting sources," ACS Nano, vol. 5, no. 6, pp. 5072-5077, 2011.

[9] X. P. Tang, A. Kleinhammes, H. Shimoda et al., "Electronic structures of single-walled carbon nanotubes determined by NMR," Science, vol. 288, no. 5465, pp. 492-494, 2000.

[10] S. Seenithurai, R. K. Pandyan, S. V. Kumar, and M. Mahendran, " $\mathrm{H}_{2}$ adsorptionin $\mathrm{Ni}$ and passivated Ni doped 4 Å single walledcarbon nanotube," International Journal of Hydrogen Energy, vol. 38, no. 18, pp. 7376-7381, 2013.

[11] M. O. Ezzat, O. H. S. Al-Obaidi, and M. N. Mordi, "Theoretical study of benzylic oxidation and effect of para-substituents by using hyperchem program," Journal of Proteomics and Bioinformatics, vol. 4, no. 5, pp. 113-115, 2011.

[12] B. Lu and Z. Zhen, "Computational study of B- or N-doped single-walled carbon nanotubes as $\mathrm{NH}_{3}$ and $\mathrm{NO}_{2}$ sensors," Carbon, vol. 45, no. 10, pp. 2105-2110, 2007.

[13] C. Kim, B. Kim, S. M. Lee, C. Jo, and Y. H. Lee, "Electronic structures of capped carbon nanotubes under electric fields," Physical Review B, vol. 65, no. 16, pp. 165418-165423, 2002.

[14] A. Maiti, J. Andzelm, N. Tanpipat, and P. Von Allmen, "Effect of adsorbates on field emission from carbon nanotubes," Physical Review Letters, vol. 87, no. 15, Article ID 155502, 2001.

[15] G. Zhang, W. Duan, and B. Gu, "Effect of substitutional atoms in the tip on field-emission properties of capped carbon nanotubes," Applied Physics Letters, vol. 80, no. 14, pp. 2589-2591, 2002.

[16] B. J. Delley, "DMOL is available commercially from BIOSYM technologies," Chemical Physics, vol. 92, pp. 508-517, 1990.

[17] L. Qiao, W. T. Zheng, H. Xu, L. Zhang, and Q. Jiang, "Field emission properties of $\mathrm{N}$-doped capped single-walled carbon nanotubes: a first-principles density-functional study," Journal of Chemical Physics, vol. 126, no. 16, Article ID 164702, 2007. 
[18] Z. Li and C. Y. Wang, "First-principles study of field emission properties of gas adsorption on the carbon nanotubes," Chemical Physics, vol. 330, no. 3, pp. 417-422, 2006.

[19] L. D. Wang, J. Q. Zhou, Q. X. Cao, and Z. Chen, "Investigation of peak separation for X-ray diffraction profiles of spinodal decomposition by a kind of optimized Voigt function," Journal of Materials Science and Technology, vol. 19, no. 4, pp. 371-373, 2003.

[20] Y. J. Wang, L. D. Wang, M. Yang, and C. Yan, "Effects of B and $\mathrm{N}$ dopings and $\mathrm{H}_{2} \mathrm{O}$ adsorption on structural stability and field emission properties of cone-capped carbon nanotubes," Chinese Physics B, vol. 20, no. 11, Article ID 117304, 2011. 

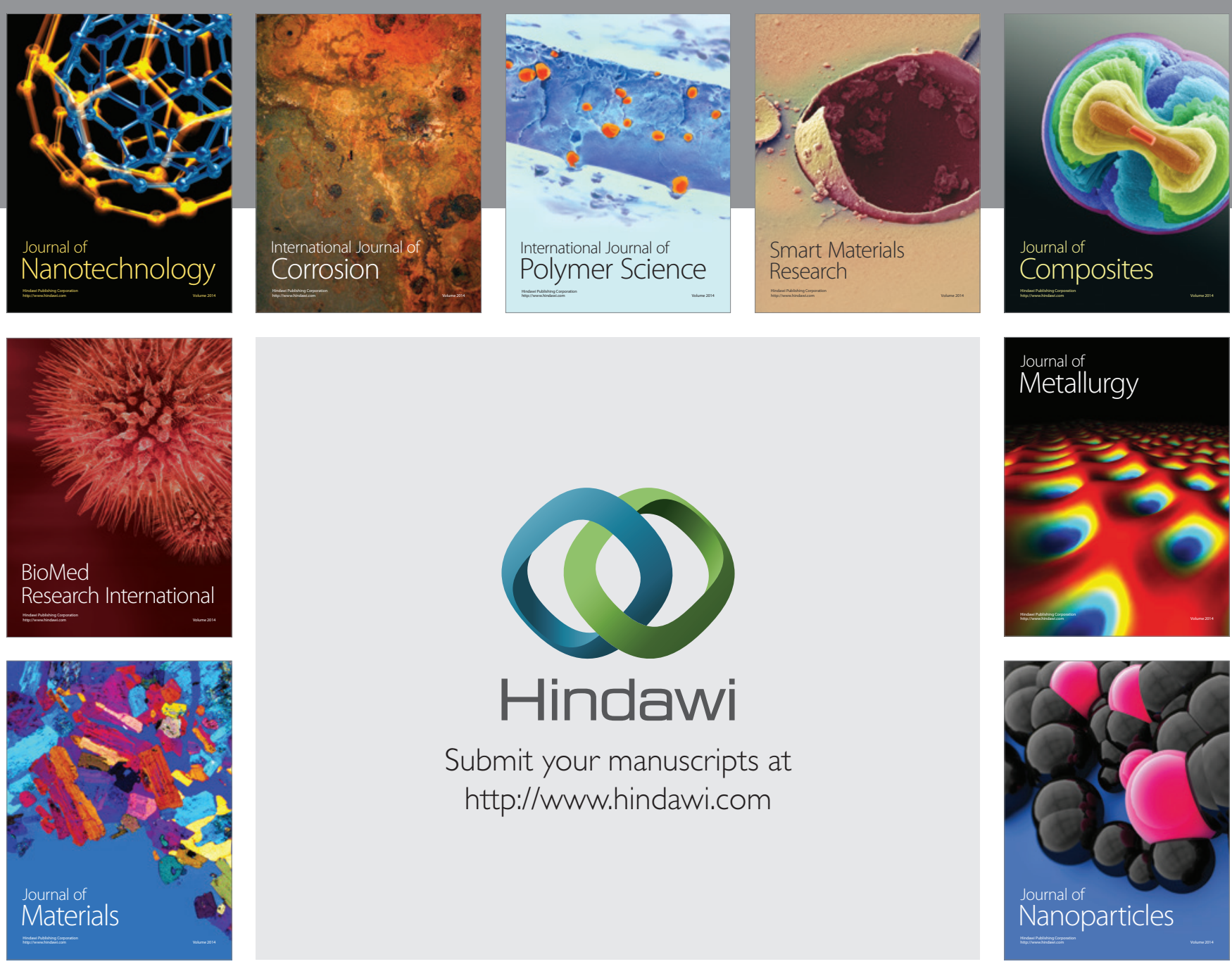

Submit your manuscripts at http://www.hindawi.com
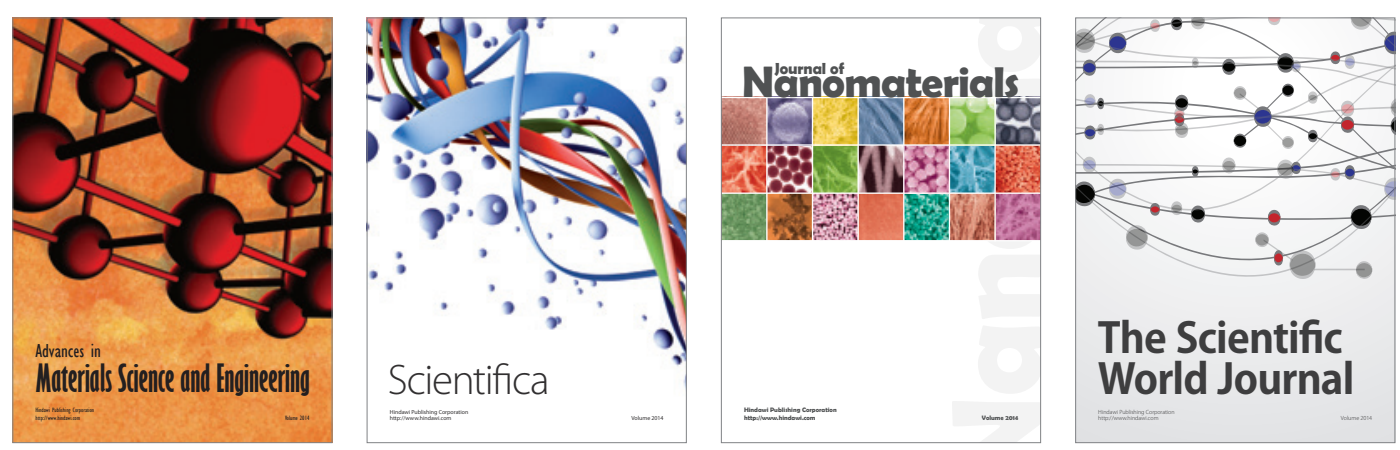

\section{The Scientific World Journal}
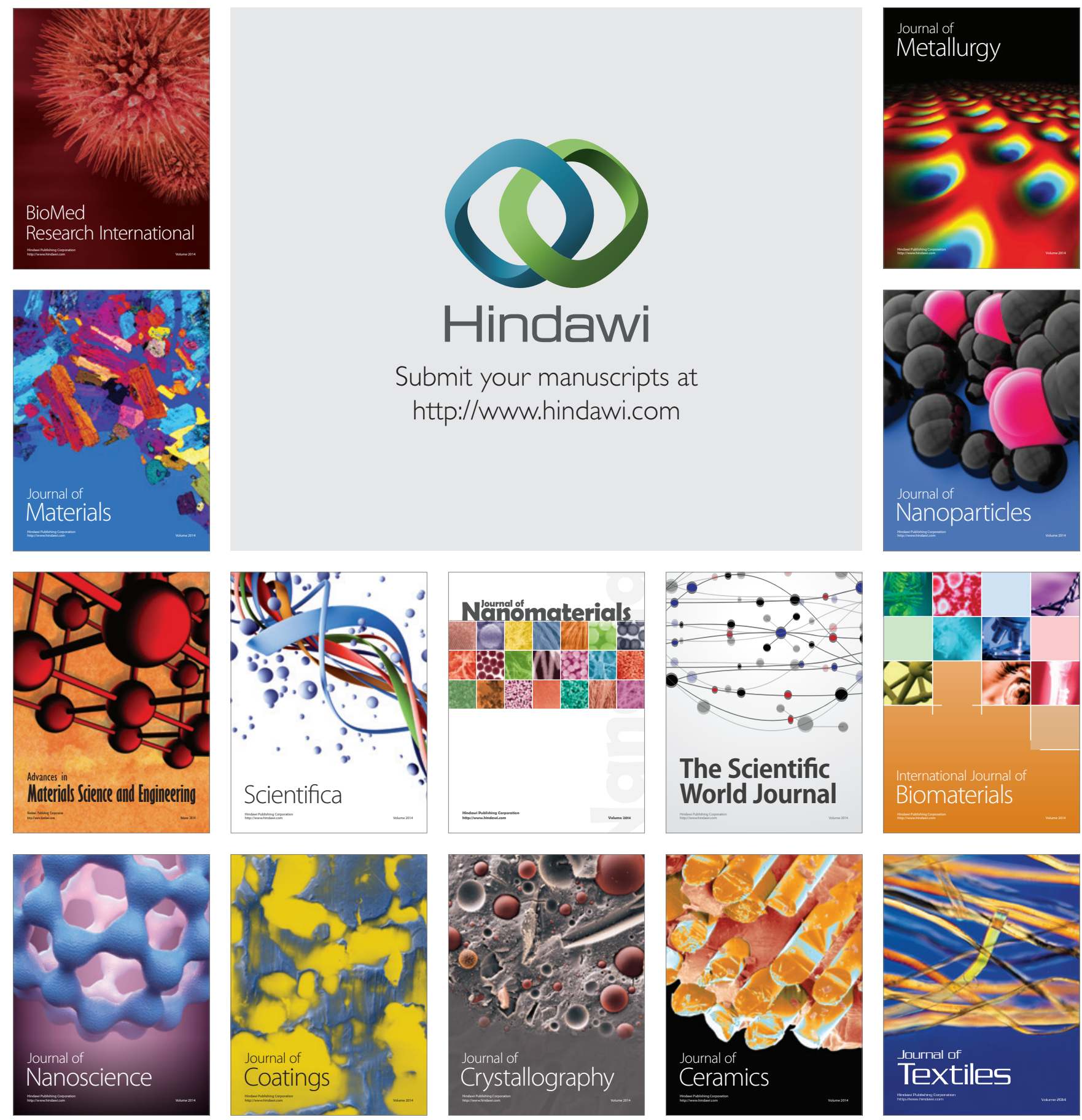